\title{
OCCUPATIONAL EXPOSURE GENE INTERACTION : REVIEW ARTICLE
}

\author{
By \\ Shaker DA \\ Department of Occupational and Environmental Medicine, Faculty of Medicine, Cairo University, Egypt.
}

\begin{abstract}
The lack of knowledge about the earliest events in occupational disease development is due to the multi-factorial nature of disease risk. This information gap is the consequence of the lack of appreciation for the fact that most occupational diseases arise from the complex interactions between genes and the occupational exposure. Whether an occupational exposure causes illness or not is dependent on the efficiency of metabolic pathways. Thus, elucidating the causes of most chronic diseases will require an understanding of both the genetic and occupational contribution to their etiology.

Unfortunately, the exploration of the relationship between genes and the occupational exposure has been hampered in the past by the limited knowledge of the human genome, and by the inclination of scientists to study disease development using experimental models that consider exposure to a single environmental agent in the workplace. To understand how genes and occupational agents interact to initiate biological pathways to cause injury or disease, scientists will need tools with the capacity to monitor the global expression of thousands of genes, proteins and metabolites simultaneously. The generation of such data in multiple species can be used to identify conserved and functionally significant genes and pathways involved in gene environment interactions. The complex interplay between genes and occupational exposure represents also a great challenge to scientists, and it is also an important opportunity to reduce the burden of disease and dysfunctions on humans.

Major technological advances in the last few years have increased our knowledge of the role that genetics has in occupational diseases and our understanding of genetic components and the interaction between genetics and environmental factors. The complex interplay between genes and occupational exposure represents also a great challenge to scientists, and it is also an important opportunity to reduce the burden of disease and dysfunctions on humans.
\end{abstract}

Key words: Gene interaction, occupational exposure, genotoxicity, polymorphism, susceptibility. 


\section{Introduction}

Genetics can play a role in all diseases. Sometimes a single gene is sufficient to trigger a disease. Other times multiple genes are involved in the disease progression. Genes may modify the individual's response in such a way that the person is more or less likely to develop a disease. For occupationallyrelated diseases no single gene will be the cause, as occupational exposure must occur. The type of exposure, extent of exposure, genes and other factors then determine the effect of the exposure in an individual (Wright, 2005).

Many of the genes in the genome of humans (human genome encodes for 50,000 to 100,000 proteins) influence the impact of environmental agents on the organism. The exact number of genes involved in the organism's response to environmental factors is unknown but could be very large (Chung et al., 2010).

Genes control cellular differentiation, division and death. When critical genetic material is altered, the functions over which it exerts control can go away, leading to birth defects, cancer, neurobehavioral abnormalities, and other diseases and dysfunctions. A better understanding of these genes, the ability of environmental agents in the workplace to interact and damage them, the relationships between a xenobiotic's chemical structure and its binding affinity to critical cellular targets, and the consequences of genetic malfunction is needed (Vineis et al., 2004).

The main influence of genetic research with respect to occupational health is the large number of technological advances in molecular biology/genetics. Because of these new techniques, it is now possible to evaluate the relationship of disease with individual genes and their variants or even with the whole genome. These technologies promise to set the stage for new discoveries in understanding mechanisms and the preclinical changes that might serve as early warnings of disease or increased risk (Barrett et al., 1997).

\section{Gene-Environment Interactions in} Occupational Safety and Health Research:

In the past, genetic information was rarely considered in epidemiological studies of occupational diseases, largely because there were no tools for precise measurement of genetic differences that might influence 
exposure-disease relationships in subsets of the population. Historically, occupational chemical exposures were so high that reasonably valid studies of exposure-disease relationships could be performed even if they did not account for genetic variation (Schulte and Halperin, 1987). However technology and information have progressed so that the relative influence of genetic factors on exposure-disease relationships is relevant as variables in study design and analysis. Interest in the role of genetic variants has emerged as a result of studies that have demonstrated variability in response to occupational exposures (Yucesoy and Luster, 2007).

The term "response variability" has been used to describe the differences in the type or magnitude of the biological effect that is due to intrinsic or acquired differences between individuals under identical exposure conditions. Various factors contribute to response variability from workplace exposures (Godderis et al., 2004).

One factor that contributes to that observed difference in response variability is individual differences in the uptake of agents. Environmental monitoring in the workplace may indicate identical exposure conditions, but what is actually absorbed into the body from that exposure may differ between individuals. Individual differences result from a range of factors that influence exposure uptake. Biological variability is one such factor. Biological variability can be further subdivided into inter-individual variability, the difference between individuals, and intra-individual variability, the difference within an individual over time (Kline et al., 2004).

Many of the metabolic processes are dependent on enzymes and other signaling molecules that are encoded by our genes. In this way, genetic variations can lead to differences in the way people react to the same toxin. For example, people who are slow 'detoxifiers' are more likely to be affected than people who can break down toxins more quickly, simply because they are exposed to the chemical for longer. When chemicals are broken down in the body, the products are usually inactive and therefore easily excreted. However, the products are sometimes more reactive and able to bind to genetic material (DNA) or other biologically important molecules. If the DNA adducts (chemicals bound to the DNA) are not eliminated by the body's 
natural repair processes, it is thought they can cause gene mutations which can eventually lead to cancer (Koh et al., 1999).

\section{GeneticSusceptibility to Occupational Exposure:}

Because of their high prevalence in the general population, genetic variants that determine susceptibility to environmental exposures may contribute greatly to the development of occupational diseases in the setting of specific exposures occurring in the workplace. Studies investigating genetic susceptibilities in the workplace may: (1) provide mechanistic insight into the aetiology of disease, in particular the determination of environmentally responsive genes; (2) identify susceptible subpopulations with respect to exposure; and (3) provide valuable input in setting occupational exposure limits by taking genetic susceptibility into account. Polymorphisms in the NAT2 and the HLA-DPB1Glu69 genes provide classic examples of how genetic susceptibility markers have a clear role in identifying disease risk in bladder cancer and chronic beryllium disease, respectively. For diseases with more complex and multifactorial aetiology such as occupational asthma and chronic airways disease, susceptibility studies for selected genetic polymorphisms provide additional insight into the biological mechanisms of disease. Even when polymorphisms for genetic susceptibility have a clear role in identifying disease risk, the value of wide scale genetic screening in occupational settings remains limited due to primarily ethical and social concerns. Thus, large scale genetic screening in the workplace is not currently recommended (Koh et al., 1999).

\section{Genetic Polymorphism :}

Genetic polymorphism is a term used to describe variants occurring at an incidence of $>1 \%$. Polymorphisms are common among humans. Some have no functional significance, and the identification of which do and which do not have any functional significance will be necessary in order to be able to interpret the information obtained in the genetic research in the workplace (Hirvonen, 1999).

Polymorphisms often affect the functions of genes but some may change the level of expression of a gene or change the activity of a gene product, for example, an enzyme. Most of the 
approximately 50 known inherited traits that could potentially enhance an individual's susceptibility are often difficult to detect. Many genetic conditions associated with enhanced susceptibility to environmental chemicals remain to be discovered. As human population is biologically diverse and genetically heterogeneous, it is not surprising that differences in susceptibility to disease among individuals with or without exposure to environmental chemicals exist (Levy, 2002).

Genetic polymorphisms contribute to biologic variability and hence may result in inter-individual variability in the uptake of agents. For this reason, gene variants are important to study when trying to explain response variability. Our knowledge of the role of gene-environment interactions in occupational diseases has increased in the past few years. Mechanistic studies have focused on the role of specific genes in the development of disease. The majority of studies have investigated carcinogen exposure and polymorphisms in the alleles of genes that code for enzymes involved in xenobiotic metabolism or biotransformation. Metabolism and transformation are intended to remove compounds from the body, but the process may result in the formation of toxic metabolites. Differences in DNA coding result in biological variability in enzymes, which ultimately affect the biotransformation process. Mechanistic studies have consistently reinforced the hypothesis that the biologic variability ultimately affects disease risk by modifying the levels of toxic metabolites (McCanlies et al., 2003).

Genetic factors may modify exposure-effect relationships. That is, the risk of effect or disease attributable to an occupational exposure can be decreased, unchanged, or increased depending on the form of interaction (e.g., additive, multiplicative, or synergistic) between the gene variant and the occupational hazard (Poulter, 2001).

In the area of occupational exposure research, some examples of polymorphisms of biotransformation enzymes that have been widely studied include glutathione S-transferase M1 (GSTM1), glutathione S-transferase theta 1 (GSTT1), cytochrome P450, family 1 , subfamily A, (aromatic compound-inducible) polypeptide 1 (CYP1A1), N-acetyltransferase 
2 (arylamine $\mathrm{N}$-acetyltransferase) (NAT2), and nicotinamide adenine dinucleotide phosphate (NADPH) dehydrogenase, quinine 1 (NQO1). Consistently, the GSTM1null genotype has been shown to be a risk factor for tobacco-related lung cancer. This association, like that of the association between GSTM1null and esophageal dysplasia, gives clues to the etiology of disease. Similarly, NAT2 is associated with arylamine-related bladder cancer, and NQO1 has been shown to be important for benzene-associated leukemia (Olshan et al., 2000).

One example that illustrates the relative effects of genes, occupational exposures, and their interaction is the role of the pro-inflammatory cytokine tumor necrosis factor (TNF-alpha) in silicosis. The TNF-alpha-308 polymorphism modifies the risk of silicosis among silica-exposed workers (Yucesoy et al., 2001).

In the above examples, genes modified the metabolism of the chemical exposure, which increased or decreased the risk of disease. Genes can also modify the body's immune response to the allergen in occupationally induced asthma. Human lymphocyte antigen (HLA) class 2 molecules have a crucial role in the immune response that occurs in occupational asthma. In one study, 67 workers with TDI induced asthma and 27 asymptomatic controls were genotyped for three HLA class 2 genes: DQA1, DQB1, and DRB1 (Mapp et al., 2000). Asthmatics were found to have a significantly higher frequency of specific alleles for DQA1 and DQB1, while controls had higher frequencies of two other alleles for DQA1 and DQB1. Taylor (2001) reported that the HLA class 2 gene, DR3, was more prevalent in occupational asthma cases induced by acid anhydrides, suggesting that there may be a contribution of HLA class 2 molecules in individual susceptibility to sensitization and asthma induction (Taylor, 2001).

Occupational asthma occurs in up to $5-10 \%$ of people exposed to diisocyanates. One study found a link between the disease and the lack of a GSTM1 gene in workers exposed to di-isocyanates, but this finding was based on a small study and has yet to be confirmed with a larger sample (Piirila et al., 2001). The study did not find any association between GSTP1 variations and risk of occupational asthma. In complete contrast, a more recent study reported that one form of GSTP1 does 
seem to protect workers against asthma if they have been exposed to toluene diisocyanate for a period of at least ten years (Mapp et al., 2002). This second study did not find any link between the disease and variations in GSTM1 and, again, the findings are questionable as they are based on only a small number of people. Such conflicting results make individual risk predictions impossible.

The statistical link between genetic variations in NAT2 and bladder cancer in people exposed to arylamines in the workplace or cigarette smoke has been relatively well studied. People are known as 'fast' or 'slow acetylators' depending on which version of the gene they have. A meta-analysis of all case-control studies found that 'slow acetylators' on average had a $40 \%$ increase in risk of bladder cancer compared to 'fast acetylators'. However, the overall picture remains complex and confusing. The risks vary between Europe and Asia and no increase in risk has been found in the USA (Marcus et al., 2000). Researchers in this field have argued that using these findings to screen workers for susceptibility to cancer would be ethically unacceptable and scientifically premature. The test's predictive value would be highly variable depending on the exposure and the population. The genetic variation in NAT2 that is thought to increase the risk of bladder cancer and it is also thought to reduce the risk of cancer of the colon (Hein et al., 2002).

Another study showed that individuals who lack the NQO1 enzyme appear to be at 2.6 times greater risk of benzene poisoning than people who do have the enzyme. Symptoms of benzene poisoning are a known risk factor for leukaemia but do not lead to cancer in every affected individual. These risks have only been demonstrated in an Asian population so the same may not necessarily be true for other groups (Nebert et al., 2002).

The same study also claimed that if an individual had a fast-acting CYP2E1 enzyme (from the family of cytochrome P450 enzymes) as well as a defective NQO1 enzyme, their risk of poisoning increased 7.6 fold. However, this finding was based on only a small number of people and, as acknowledged by the researchers, relied upon a rather imprecise measure of CYP2E1 enzyme activity. Other studies that have attempted to link genetic variations in NQO1 with other cancers have produced inconclusive results (Smith, 1999). 
Different forms of the paraoxonase enzyme metabolize organophosphates at different rates. In one study, a slow form of the enzyme was more commonly found in British farmers who attributed their ill-health to sheep dip (Cherry et al., 2002). However, many other factors, such as age and diet, have an effect on the metabolism of organophosphates. Researchers have also argued that for PON1 (as with many other metabolic enzymes), it is necessary to measure the actual activity of the enzyme and not just look at the genetic variation if the rate of toxin metabolism is to be accurately predicted (Brophy et al., 2000).

A specific example of research in the characterization of a genetic polymorphism of a commonly occurring gene now leads us to begin to understand the relationship between lead exposure levels and cognitive impairment in susceptible subpopulations in children. An enzyme of the heme biosynthesis pathway, delta aminolevulinate dehydratase (ALAD) is a protein that is encoded by a gene in the 9q34 chromosome locus. It is polymorphic in the population, with two common alleles, ALAD-1and ALAD-2. This structure results in three distinct genotypes, ALAD1-1 and 2-2, which are distributed in the population. It is hypothesized that individuals

With the ALAD 2 allele could be more susceptible to lead exposure if ALAD subunit binds tightly ALAD-1 subunit. Individuals with ALAD 1-2, 2-2 allele might have higher blood concentrations as well as higher total body burden, making them more likely to show clinical and subclinical manifestations of low blood levels (Shostak, 2003).

\section{The Effect of Occupational and Environmental Exposures on Genetic Material:}

Damage to DNA or other hereditary material of somatic cells can be used to evaluate exposures and, potentially, disease risk. A variety of genetic biomarkers has been used to show exposure or effects from occupational exposures (Abdel-Rahman et al., 2005); Somatic mutations, DNA adducts and protein adducts, and cytogenetic changes have frequently been used as biological measures of exposure and, in some cases, as biomarkers of effect (Albertini et al., 2003).

Whether these changes are biomarkers of effect, and ultimately 
risk factors for disease, depends on the extent to which the association with the disease has been affirmed. While numerous cross-sectional studies have consistently identified cytogenetic changes associated with exposures to genotoxic substances or agents, only longitudinal analysis is best suited to identify which genetic biomarkers are risk factors for disease. For example, using prospective designs, an increase in chromosomal aberrations has been associated with an increased risk of cancer development (Boffetta et al., 2007 and Bonassi et al., 2007).

Gene activity also can be altered without changing the DNA sequence. Various epigenetic processes including methylation, acetylation, phosphorylation, ubiquitylation, and sumolyation as well as chromatin modification can affect gene activity. A wide variety of illnesses, behaviors, and health indicators have some level of evidence linking them with epigenetic mechanisms, including cancers, cognitive dysfunction, respiratory, cardiovascular, reproductive, autoimmune and neurobehavioral illnesses.Heavymetals, pesticides, diesel exhaust, tobacco smoke, polycyclic hydrocarbons, hormones, radioactivity, viruses, bacteria, and nutrients are known or suspected to influence epigenetic processes (Weinhold et al., 2006). While a comprehensive view of epigenetics in relation to occupational disease still has not been developed, a large role and further research is necessary since epigenetics may have a role in understanding occupational and environmental causes of diseases (Wade and Archer, 2006).

\section{Chromosomal Aberrations:}

One of the few direct methods for measuring gross changes in DNA involves visualization of the chromosomes through the light microscope. The viewer might see overt breakage and rearrangement of the chromosomes within the cell as well as more subtle changes involving the exchange of material between chromatics of a chromosome. CAs are usually induced by agents that can directly break the DNA duplex such as different types of radiation chemicals that imitate the effects of radiation. CAs therefore serve as a biological dosimeter in individuals exposed to ionizing radiation. The same is not true for cases of chemical exposure, however, since most clastogenic chemicals require metabolic activation and are dependent 
on a critical time in DNA replication. CAs have been demonstrated for a large number of chemicals in vitro, but relatively few chemicals have been convincingly shown to increase CAs in vivo (Bilban et al., 2005). On the other hand, some investigators have reported that in vivo cytogenetic assay is a very accurate assay system to identify carcinogens from non-carcinogens (Celi and Akbas, 2005).

\section{Sister Chromatid Exchange:}

The study of SCEs is an indirect indicator of mutation, although the biological significance is unknown. Unlike CA measurements, SCE can be a sensitive marker for the measurement of DNA damage and repair (Mrdjanovic et al., 2005). Sister chromatics are the two daughter strands of a duplicated chromosome. SCEs are events that occur when apparently equivalent sections of the sister chromatics of the same chromosome are exchanged during cell division (mitosis). SCEs occur in cells at a normal rate, but appear to be elevated when exposed to agents that damage DNA. Of importance from a practical standpoint, SCEs appear to result only as an effect of chemical mutagens, not radiation. They are most efficiently induced by substances that form covalent adducts to the DNA, distort the DNA helix, or interfere with DNA precursor metabolism or repair (Medeiros et al., 2003).

\section{Micronuclei Assay:}

One consequence of the induction of CAs is the formation of micronuclei, which result from the exclusion of fragments of/or whole chromosomes from nuclei formed at mitosis. The presence of micronuclei can be taken as an indication of the previous existence of CAs. Micronuclei are far easier to score than CAs at metaphase (although less frequent) and provide a simple means for estimating induced genetic damage. In addition, micronuclei persist for varying lengths of time after their formation so they can be detected in non-dividing descendants of cells. Early studies of the effects of ionizing radiation on mitosis showed that the frequency of micronuclei was dependent on radiation dose (Migliore et al., 2006). 
Examples of Genetic damage by occupational exposure:

Sister Chromatid Exchanges :

- Anesthetic gases (Bilban et al., 2005).

- Gasoline (Celi and Akbas, 2005).

- Styrene (Teixeira et al., 2004).

Micronuclei:

- Ionizing radiation (Mrdjanovic et al., 2005).

- Trivalent chromium (Medeiros et al., 2003).

- PAH (Pavanello et al., 2008).

- Styrene (Migliore et al., 2006).

Chromosomal Aberrations:

- Benzene (Holeckova et al., 2004).

- X-rays (Milacic, 2005).

- Fenvalerate (Xia et al., 2004).

DNA strand breaks:

- Roofing Asphalt (Toraason et al., 2001).

- Bitumen (Marczynski et al., 2006).

- Antineoplastic drugs (Deng et al., 2005).

\section{DNA Adducts}

- Smoking (Taioli et al., 2007).

- PAH (Peters et al., 2008).

- Diesel exhausts (Arlt et al., 2007).

\section{Oncogene Mutations}

- Arsenic (Wen et al., 2008).

- Coal emissions (Keohavong et al., 2005). 
The value of any genetic test is dependent on the prevalence of the disease and genetic trait in the population and the relative risk of disease for those carrying the trait. This issue has been demonstrated practically for HLADPB1 (Weston et al., 2002) which has been implicated as a susceptibility gene in beryllium hypersensitivity and CBD (McCanlies and Weston, 2004).

\section{Occupational exposure may induce protective protein:}

Other exposures may induce the synthesis of a protective protein in the body. The best example is probably metallothionin, which binds cadmium and promotes the excretion of this metal; cadmium exposure is one of the factors that result in increased expression of the metallothionin gene. Similar protective proteins may exist but have yet been explored sufficiently to become accepted as biomarkers. Among the candidates for possible use as biomarkers are the so called stress proteins, originally referred to as heat shock proteins. These proteins are generated by a range of different organisms in response to a variety of adverse exposures (Khoury et al., 1993).

\section{Detection of workers at risk for genetic damage:}

As used in the workplace, genetic testing encompasses two activities: genetic monitoring and genetic screening. Thus, genetic testing of employee populations involves both examining persons for evidence of induced change in their genetic material (monitoring) and identifying individuals with particular inherited traits or disorders (screening) (Bingham, 1998).

\section{What is Genetic Monitoring?}

Genetic monitoring involves periodically examining employees to evaluate modifications of their genetic material, e.g., chromosomal damage or evidence of increased occurrence of molecular mutations that might have evolved in the course of employment. The putative cause is workplace exposure to hazardous substances. The premise is that such changes could indicate increased risk of future illness (Burris et al., 2000).

Because ambient exposures, personal habits and lifestyle decisions (e.g., tobacco use, etc.), and age can also induce changes in genetic material, genetic monitoring could detect changes that arise from exposures outside of the 
workplace. Genetic monitoring could be performed on groups of employees to identify the risk for the exposed group as a whole, to target work areas for increased safety and health precautions, and to indicate a need to lower exposure levels for a group exposed to a previously unknown hazard (Blakely et al., 2001).

\section{What is Genetic Screening?}

Genetic screening involves assays to examine the genetic makeup of employees or job applicants for certain inherited characteristics. (Employees could be screened on different occasions for different traits or with improved technology, but generally only once per characteristic.) Genetic screening can be used in two distinct ways. First, employees or job applicants could be screened for the presence of genetically determined traits that render them susceptible to a pathological effect if exposed to specific agents. For example, an employee or a job applicant could be tested to identify a genetic predisposition to an occupationally related disease. Second, employees or job applicants could be screened to detect general heritable conditions, not just conditions associated with occupational illness (CDC, 2007).
Reasons for using the different classes of tests vary. In either case, whether screening for an occupationally related trait or one unrelated to job exposure, genetic screening tests involve examinations for inherited traits where a single measure is usually sufficient because these inherited characteristics, as a rule, do not change. Genetic screening for occupationally related traits could be performed to ensure appropriate worksite placement of employees susceptible to certain occupational diseases, and ensure that employers place those workers most susceptible to a specific risk in the least hazardous environments. Both genetic screening for occupationally related traits and for non occupationally related traits could be performed to: improve employee productivity and lower workers' compensation costs through better worker health; promote and encourage general health awareness; and improve employers' health care cost-containment efforts, especially for health insurance. This could be done through exclusion (i.e., not hiring those with deleterious genes because of the potential drain on health insurance). Genetic screening differs significantly from genetic monitoring. With screening, a one-time test to detect a 
single trait in a worker or job applicant is usually sufficient, while monitoring generally involves multiple tests of a worker over time. Most importantly, genetic screening focuses on the preexisting genetic makeup that workers or job applicants bring to the job. This is distinct from genetic monitoring which focuses on hazardous workplace exposures that induce changes in the genetic material (CDC, 2007).

As genetic testing procedures lower in cost with improved technology, it is possible or likely that more employers will implement such testing of applicants and employees. Even if employers do not engage in genetic testing, they may have the ability to gather the same or similar information about genetic predispositions from independent sources or from questions concerning an employee's family history as part of pre-employment or employment medical examinations (Lauro, 2006).

\section{Conclusion}

Understanding the role of genetic factors and their interaction with occupational exposures is important in occupational health and could lead to further prevention and control efforts, the identification of novel therapeutic targets and educational strategies for better management of work-related diseases. Although the majority of workplace exposures are being highly controlled, workers with susceptible genetic profiles may still be at high risk. Occupational safety and health decision-makers, researchers, and practitioners may ultimately find that genetic factors contribute substantially to some occupational diseases but not to others. Occupational/environmental risk factors should always be more important for developing strategies for prevention and intervention in occupational disease and ultimately for the reduction of morbidity and mortality. The challenge is to identify and apply genetic information in ways that will improve occupational safety and health for workers.

\section{References}

1. Abdel-Rahman SZ, Ammenheuser MM, Omiecinski CJ, Wickliffe JK, Rosenblatt JI and Ward JB Jr (2005): Variability in human sensitivity to 1,3-butadiene: influence of polymorphisms in the 5'-flanking region of the microsomal epoxide hydrolase gene (EPHX1). Toxicol Sci; 85:624-631.

2. Albertini RJ, Sram RJ, Vacek PM, Lynch J, Nicklas JA, van Sittert NJ, Boogaard PJ, Henderson RF, Swenberg JA, Tates AD, Ward JB Jr., Wright M, Ammenheuser MM, Binkova B, Blackwell W, de Zwart FA, Krako D, Krone J, Megens H, Musilova P, Rajska G, Ranasinghe A, Rosenblatt JI, Rossner P, Rubes 
J, Sullivan L, Upton $\mathrm{P}$ and Zwinderman AH (2003): Biomarkers in Czech workers exposed to 1,3-butadiene: a transitional epidemiologic study. Res Rep Health Eff Inst; 116:1-141.

3. Arlt VM,GlattH, Gamboa da Costa G, Reynisson J, Takamura-Enya T and Phillips DH (2007): Mutagenicity and DNA adduct formation by the urban air pollutant 2-nitrobenzanthrone. Toxicol Sci; 98:445-457.

4. Barrett JC, Vainio H, Peakall D and Goldstein BD (1997): 12th Meeting of the scientific group on methodologies for the safety evaluation of chemicals: susceptibility to environmental hazards. Environ Health Perspect; 105:699-737.

5. Bilban M, Jakopin CB and Ogrinc D (2005): Cytogenetic tests performed on operating room personnel (the use of anaesthetic gases). Int Arch Occup Environ Health; 78:60-64.

6. Bingham E (1998): Ethical issues of genetic testing for workers. In: Mendelsohn ML, Mohr LC and Peeters JP, eds. Biomarkers: medical and workplace applications. Washington, DC: Joseph Henry Press; 415-422.

7. Blakely WF, Prasanna PGS, Grace MB and Miller AC (2001): Radiation exposure assessment using cytological and molecular biomarkers. Radiat Prot Dosimetry; 97:17-23.

8. Boffetta $\mathrm{P}$, van der Hel O, Norppa $\mathrm{H}$, Fabianova E, Fucic A, Gundy S, Lazutka J, Cebulska- Wasilewska A, Puskailerova D, Znaor A, Kelecsenyi Z, Kurtinaitis J, Rachtan J, Forni A, Vermeulen R and Bonassi S (2007): Chromosomal aberrations and cancer risk: Results of a cohort study from central Europe. Am J Epidem; 165:36-43.

9. Bonassi S, Znaor A, Ceppi M, Lando C, Chang WP, Holland N, Kirsch-Volders M, Zeiger E, Ban S, Barale R, Bigatti MP, Bolognesi C, Cebulska-Wasilewska A, Fabianova E, Fucic A, Hagmar L, Joksic G, Martelli A, Migliore L,
Mirkova E, Scarfi MR, Zijno A, Norppa H and Fenech M (2007): An increased micronucleus frequency in peripheral blood lymphocytes predicts the risk of cancer in humans. Carcinogenesis; 28:625-631.

10. Brophy VH, Jarvik GP, Richter RJ, Rozek LS, Schellenberg GD and Furlong GE (2000): Analysis of paraoxonase (PON1) L55M status requires both genotype and phenotype. Pharmacogenetics; 10: 453-60.

11. Burris S, Gostin LO and Tress D (2000): Public health surveillance of genetic information: ethical and legal responses to social risk. In: Khoury MJ, Burke W and Thomson EJ, eds. Genetics and public health in the 21st century; using genetic information to improve health and prevent disease. New York: Oxford University Press; 527-548.

12. CDC (Centers for Disease Control and Prevention) (2007): Genetic testing. [http:// www. cdc.gov/genomics/gtesting.htm]. Date accessed: July.

13. Celi KA and Akbas E (2005): Evaluation of sister chromatid exchange and chromosomal aberration frequencies in peripheral blood lymphocytes of gasoline station attendants. Ecotoxicol Environ Saf; 60:106-112.

14. Cherry N, Mackness M, Durrington P, Povey A, Dippnall M, Smith T et al. (2002): Paraoxonase (PON1) polymorphisms in farmers attributing ill health to sheep dip. The Lancet; 359: 763-4.

15. Chung CC, Magalhaes WCS, Gonzalez-Bosquet J and Chanock SJ (2010): Genome-wide association studies in cancer - current and future directions. Carcinogenesis; 31(1):111-120.

16. Deng H, Zhang M, He J, Wu W, Zheng W, Lou $\mathrm{J}$ and Wang B (2005): Investigating genetic damage in workers occupationally exposed to methotrexate using three genetic end-points. Mutagenesis; 20:351-357. 
17. Godderis L, De Boeck M, Haufroid V, Emmery M, Mateuca R, Gardinal S, Kirsch-Volders M, Veulemans H and Lison D (2004): Influence of genetic polymorphisms on biomarkers of exposure and genotoxic effects in styreneexposed workers. Environ Molec Mut; 44:293303.

18. Hein DW (2002): Molecular genetics and function of NAT1 and NAT2: role in aromatic amine metabolism and carcinogenesis. Mutation Research; 506-507: 65-77.

19. Hirvonen A (1999): Polymorphism of Xenobiotic-Metabolizing Enzymes and Susceptibility to Cancer. Environmental Health Perspectives; 107(1):37-47.

20. Holeckova B, Piesova E, Sivikova K and Dianovsky J (2004): Chromosomal aberrations in humans induced by benzene. Ann Agric Environ Med; 11:175-179.

21. Keohavong P, Lan Q, Gao W-M, Zheng K-C, Mady HH, Melhem MF and Mumford JL (2005): Detection of p53 and K-ras mutations in sputum of individuals exposed to smoky coal emissions in Xuan Wei County, China. Carcinogenesis; 26:303-308.

22. Khoury M, Beaty $T$ and Cohen B (1993): Fundamentals of genetic epidemiology. New York: Oxford University Press.

23. Kline JN, Doekes G, Bonlokke J, Hoffman HJ, Von Essen S and Zhai R (2004): Working group report 3: sensitivity to organic dusts - atopy and gene polymorphisms. Am J Ind Med; 46:416418.

24. KohD, Seow A and Ong CN (1999): Applications of new technology in molecular epidemiology and their relevance to occupational medicine. Occupational and Environmental Medicine; 56: 725-9.

25. Lauro SK (2006): Business And Commercial Law The Science of Discrimination: Genetics in the American Workplace. GPSolo Magazine.;35-40.

26. Levy LS (2002): Variability and susceptibility to occupational and environmental contaminants. In: Institute for Environment and Health, ed. Variability and susceptibility in human response to occupational exposure to chemicals in the UK (Report R13), pp 48-57. Leicester, UK: MRC Institute for Environment and Health.

27. Mapp CE, Beghe B, Balboni A, et al. (2000): Association between HLA genes and susceptibility to toluene diisocyanate-induced asthma. Clin Exp Allergy; 30(5):651-656.

28. Mapp CE, Fryer AA, De Marzo N, Pozzato V, Padoan M,Boschetto P, et al.(2002): Glutathione S-transferase GSTP1 is a susceptibility gene for occupational asthma induced by isocyanates. Journal of Allergy and Clinical Immunology; 2002; 109: 867- 72.

29. Marcus PM, Vineis P and Rothman N (2000): NAT2 slow acetylation and bladder cancer risk: A meta-analysis of 22 case-control studies conducted in the general population. Pharmacogenetics; 10: 115-22.

30. Marczynski B, Raulf-Heimsoth M, Preuss R, Kappler M, Schott K, Pesch B, Zoubek G,Hahn JU, Mensing T, Angerer J, Kafferlein HU and Bruning T (2006): Assessment of DNA damage in WBCs of workers occupationally exposed to fumes and aerosols of bitumen. Cancer Epidemiol Biomarkers Prev; 15:645-651.

31. McCanlies E and Weston A (2004): Immunogenetics of chronic beryllium disease. In: Khoury ML, Little J and Burke W, eds. Human genome epidemiology: a scientific foundation for using genetic information to improve health and prevent disease. New York: Oxford University Press; 383-401.

32. McCanlies EC, Kreiss $\mathrm{K}$, Andrew $\mathrm{M}$ and Weston A (2003): HLA-DPB1 and chronic 
beryllium disease: a HuGE review. Am J Epidemiol; 157:388-398.

33. Medeiros MG, Rodrigues AS, Batoreu MC, Laires A, Rueff J and Zhitkovich A (2003): Elevated levels of DNA-protein crosslinks and micronuclei in peripheral lymphocytes of tannery workers exposed to trivalent chromium. Mutagenesis; 18:19-24.

34. Migliore L, Naccarati A, Coppede F, Bergamaschi E, De Palma G, Voho A, Manini $\mathrm{P}$, Jarventaus $\mathrm{H}$, Mutti A, Norppa $\mathrm{H}$ and Hirvonen A (2006): Cytogenetic biomarkers, urinary metabolites and metabolic gene polymporphisms in workers exposed to styrene. Pharmacogenet Genomics; 16:87-99.

35. Milacic S (2005): Frequency of chromosomal lesions and damaged lymphocytes of workers occupationally exposed to $\mathrm{x}$ rays. Health Phys; 88:334-339.

36. Mrdjanovic J, Jakimov D, Tursijan S and Bogdanovic G (2005): Evaluation of sister chromatid exchanges, micronuclei, and proliferating rate index in hospital workers chronically exposed to ionizing radiation; J BOUN. 10:99-103.

37. Nebert DW, Roe AL, Vandale SE, Bingham E and Oakley GG (2002): NAD(P)H: quinine oxidoreductase (NQO1) polymorphism, exposure to benzene and predisposition to disease. Genetics in Medicine; 4: 62-70.

38. Olshan AF, Weissler MC, Watson MA and Bell DA (2000): GSTM1, GSTT1, GSTP1, CYP1A1, and NAT1 polymorphisms, tobacco use, and the risk of head and neck cancer. Cancer Epidemiol Biomarkers Prev; 9:185-191.

39. Pavanello S, Kapka L, Siwinska E, Mieizynska D, Bolognesi C and Clonfero E (2008): Micronuclei related to anti-B[a]PDE-DNA adduct in peripheral blood lymphocytes of heavily polycyclic aromatic hydrocarbon- exposed nonsmoking coke-oven workers and controls. Cancer Epidemiol Biomarkers Prev; 17:2795-2799.

40. Peters S, Talaska G, Jonsson BA, Kromhout H and Vermeulen R (2008): Polycyclic aromatic hydrocarbon exposure, urinary mutagenicity, and DNA adducts in rubber manufacturing workers. Cancer Epidemiol Biomarkers Prev; 17:1452-1459.

41. Piirila P, Wikman H, Luukkonen R, Kaaria $\mathrm{K}$, Rosenberg C, Nordman H, Norppa H, Vainio H and Hirvonen A (2001): Glutathione S-transferase genotypes and allergic responses to diisocyanate exposure. Pharmacogenetics; 11:437-445.

42. Poulter SR (2001): Genetic testing in toxic injury litigation: the path to scientific certainty or blind alley? Jurimetrics J ; 41:211-238.

43. Schulte PA and Halperin WE (1987): Genetic screening and monitoring in the workplace. In: Harrington JM, ed. Recent advances in occupational health. Vol. 3. Edinburgh, Scotland, U.K.: Churchill Livingstone; 135154.

44. Shostak S (2003): Locating gene-environment interaction: at the intersections of genetics and public health. Soc Sci Med; 56:2327-2342.

45. Smith MT (1999): Benzene, NQO1 and genetic susceptibility to cancer. Proceedings of the National Academy of Sciences USA; 96: 76246.

46. Taioli E, Sram RJ, Binkova B, Kalina I, Popov TA, Garte S and Farmer PB (2007): Biomarkers of exposure to carcinogenic PAHs and their relationship with environmental factors. Mutat Res; 620:16-21.

47. Taylor AN (2001): Role of human leukocyte antigen phenotype and exposure in development of occupational asthma. Curr Opin Allergy Clin Immunol; 1:157-161. 
48. Teixeira JP, Gaspar J, Silva S, Torres J, Silva SN, Azevedo MC, Neves P, Laffon B, Mendez J, Goncalves C, Mayan O, Farmer PB and Rueff J (2004): Occupational exposure to styrene: modulation of cytogenetic damage and levels of urinary metabolites of styrene by polymorphisms in genes CYP2E1, EPHX1, GSTM1, GSTT1 and GSTP1. Toxicology; 195:231-242.

49. Toraason MA, Hayden C, Marlow D, Rinehart R, Mathias P, Werren D, DeBord DG and Reid TM (2001): DNA strand breaks, oxidative damage, and 1-OH pyrene I roofers with coal tar pitch dust and /or asphalt fume exposure. Int Arch Occup Environ Health; 74:396-404.

50. Vineis P, Schulte PA, Carreon T, Bailer AJ and Medvedovic M (2004): Issues in design and analysis of gene environment interactions. In: Mechanisms of carcinogenesis. Buffler P, Rice J, Baan R, Bird M and Boffeta P (eds). IARC, Lyon France. IARC Sci Publ; 157:417-436.

51. Wade PA and Archer TK (2006): Epigenetics: environmental instructions for the genome. Environ Health Perspect; 114:A140-A141.

52. Weinhold B (2006): Epigenetics: the science of change. Environ Health Perspect; 114:A160-A167.
53. Wen W, Che W, Lu L, Yang J, Gao X, Wen J, Heng Z, Cao S and Cheng H (2008): Increased damage of exon 5 of p53 gene in workers from an arsenic plant. Mutat Res; 643:36-40.

54. Weston A, Ensey J, Kreiss K, Keshava C and McCanlies EC (2002): Racial differences in prevalence of a supratypic HLA-genetic marker immaterial to pre-employment testing for susceptibility to chronic beryllium disease. Am J Ind Med; 41:457-465.

55. Wright L (2005): Understanding Genetics: A Primer for Occupational Health Practice. AAOHN Journal; 53(12).

56. Xia Y, Bian Q, Xu L, Cheng S, Song L, Liu J, Wu W, Wang S and Wang X (2004): Genotoxic effects on human spermatozoa among pesticide factory workers exposed to fenvalerate. Toxicology; 203:49-60.

57. Yucesoy B and Luster MI (2007): Genetic susceptibility in pneumoconiosis. Toxicol Lett; 168:249-254.

58. Yucesoy B, Vallyathan V, Landsittel DP, Sharp DS, Weston A, Burleson GR, Simeonova P, McKinstry M and Luster MI (2001): Association of tumor necrosis factor- $\alpha$ and interleukin1gene polymorphisms with silicosis. Toxicol Appl Pharmacol; 172:75-82. 